\title{
FEA ANALYSIS OF BENDING STRESS AND DEFLECTION IN THIN STEEL SHEET WITH REINFORCING RIBS CREATED BY LASER TREATMENT
}

\author{
'Oleksandr KAPUSTYNSKYI, 'Nikolaj VIŠNIAKOV \\ 1Vilnius Gediminas Technical University, Vilnius, Lithuania, EU, oleksandr.kapustynskyi@vgtu.It
}

https://doi.org/10.37904/metal.2020.3533

\begin{abstract}
The main objective of the research was to determine the influence of local laser treatment on the process of elastoplastic deflection of the sheets under bending force. FEA modelling results show, that the location of the treated area and the number of laser tracks on a thin-walled sheet surface had a large influence on the stress distribution and sheet deflections during bending. The FEA analysis of equivalent Von-Mises stresses, normal stresses, deflection of steel sheets and applied bending forces confirms that the steel samples with the lasertreated area have greater resistance against bending and reduced deflection under the same bending forces. FEA investigation shows that a greater strengthening effect on thin-walled steel sheets could be achieved through the application of double-sided laser treatment of the sheet surface in comparison with untreated or one-side treated steel sheets.
\end{abstract}

Keywords: Hypoeutectoid steel, thin-walled sheet metal, reinforcing ribs, laser treatment, FEA modelling

\section{INTRODUCTION}

Current methods to increase the mechanical stiffness of thin-sheet metals are mainly design methods based on the relationship between construction geometry and stiffness. The creation of ribs or thick areas increase stiffness, but this also leads to an increase of the dimensions and weight of the final products [1]. The new metal processing technologies enables manufacturers to control and improve the properties of metals and metalworking products. Laser treatment is one such modern technique, which can be applicable for this purpose. Local laser-induced heating allows the creation of local areas with structure, hardness and overall mechanical properties differing with the rest of the metallic structure [2]. Laser heat treatment (LTH) is a heating and surface modification process of the base material, which helps to locally initiate a transition of the structural phases of treated by laser metal and change the microstructure and properties of this metal areas; for instance, it may increase their stiffness or hardness. Therefore, such a technique can significantly reduce the total weight of the steel product and increase the most important mechanical properties of specific structural elements at the same time [3]. Prediction of the mechanical properties of the laser-treated zones, as well as the prediction of distribution and values of the internal stresses and mechanical deformations that occur in the whole thinsheet structure after laser treatment under a working force, helps to control and affect the rigidity or stiffness of the such metallic structure significantly. Finite element analysis (FEA) is an powerful numerical and design tool for nonlinear mechanical analysis of bended structures. FEA models can be generated for all design concepts considered. The FEA model and nonlinear mechanical analysis of bending stress distribution and deflection of thin steel sheets treated by laser for their strengthening are presented in this work. The efficiency of local laser processing for strengthening of structural elements made from thin sheet steel discussed in this paper. The influence of varying the amounts, distance and location between the laser tracks on the final bending stress distribution and deflection of thin sheet samples was analysed by the FEA method. 


\section{AIM OF THE STUDY}

The main goal of this study was to simulate and analyse the influence of laser treatment on the elastoplastic deflection of steel sheets under a bending force. The mechanical properties of the laser-treated zones were predicted taking into account the results of previous experimental research of the microstructure and hardness of the laser-treated zone of a thin sheet of similar low carbon steel. Several 3D models of the bended sheet were created, varying the quantity and distance between the laser tracks.

\section{OBJECT OF THE STUDY}

Steel is one of the most important constructional materials around the world [4]. Approximately, 20 billion tonnes of steel manufactured in the world each year and represents around $95 \%$ of all produced metals [5]. High-quality low carbon steel is one of the most popular and largest groups of structural steels, which typically contain from $0.04 \%$ to $0.30 \%$ carbon content. Most steels used throughout Europe are specified to comply with European standards EN 10025 and EN 10250. Structural high-quality carbon steel (1.1158, C25E) containing less than $0.3 \%$ carbon was used in this work (Table 1). Typical chemical composition of this hypoeutectoid steel (in wt\%): 0.22 - 0.29C; max 0.40Si; $0.40-0.70 \mathrm{Mn}$; max 0.035S; max 0.035P; max 0.63 $(\mathrm{Cr}+\mathrm{Mo}+\mathrm{Ni})$. The microstructure and mechanical properties of this hypoeutectoid steel according to standard EN 10250-2 can vary depending on the heat treatment [6].

Table 1 Mechanical properties of steel 1.1158 [7]

\begin{tabular}{|c|c|c|c|c|}
\hline $\begin{array}{c}\text { Elastic modulus } \\
\text { E (GPa) }\end{array}$ & $\begin{array}{c}\text { Yield strength } \\
\mathbf{R}_{\mathbf{0 . 2}} \text { (Mpa) }\end{array}$ & $\begin{array}{c}\text { Tensile strength } \\
\mathbf{R m}(\mathbf{M p a})\end{array}$ & $\begin{array}{c}\text { Relative extension } \\
\mathbf{( \% )}\end{array}$ & $\begin{array}{c}\text { Hardness (HV) } \\
(-)\end{array}$ \\
\hline $190-200$ & Min 230 & 440 & Min 23 & 142 \\
\hline
\end{tabular}

\section{METHODOLOGY OF RESEARCH}

Version 16 software was used for FEA simulation of the elastoplastic deflection of laser-treated thin sheet metal under a bending force. Appropriate mesh models of laser-treated thin sheet metal plates were generated, taking into account the real geometry of the sheet sample and quantity of treated layers; physical properties of the steel and treated layer, character of metal stress-strain curves, value of bending force and boundary conditions. The dimensions of the thin sheet metal $100 \times 30 \times 2 \mathrm{~mm}$, area of laser-treatment $40 \times 30 \mathrm{~mm}$, depth of treatment $0.35 \mathrm{~mm}$ are identical in all FEA models. The area of laser treatment was located in the zone of maximum internal stresses. Three variants of dislocation of the laser-treated area on a sheet (on the top, bottom and both sides) was applied. Three variants of distances between the laser-treated tracks (with overlap, distances of $0.35 \mathrm{~mm}$ and $0.7 \mathrm{~mm}$ ) (Figure 1, Table 2) are used.
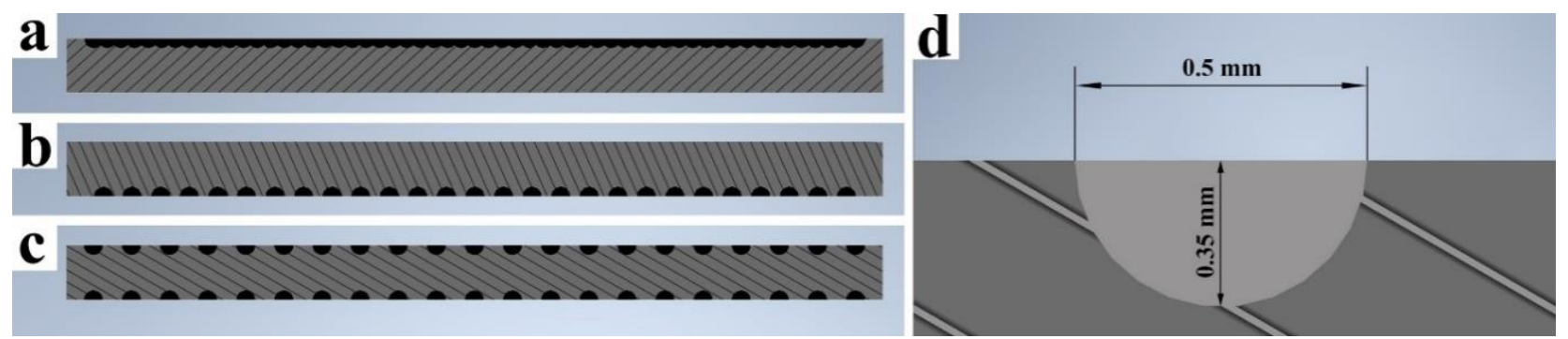

Figure 1 Cross-section view of laser treated sample: a - case I-I; b - case II-II; c - case III-III; d - crosssection view of laser track 
Table 2 Variants of FEA model geometry

\begin{tabular}{|c|c|c|c|}
\hline $\begin{array}{c}\text { Location of laser- } \\
\text { treated area }\end{array}$ & $\begin{array}{c}\text { Distances between the } \\
\text { laser-treated tracks } \\
(\mathbf{m m})\end{array}$ & $\begin{array}{c}\text { Number of laser tracks in } \\
\text { treated area } \\
\text { (pcs) }\end{array}$ & Abbreviation of case \\
\hline \multirow{3}{*}{ On the top } & Overlap & 57 & I-I \\
\cline { 2 - 4 } & 0.35 & 27 & I-II \\
\cline { 2 - 4 } & 0.7 & 21 & I-III \\
\cline { 2 - 4 } & Overlap & 57 & II-I \\
\cline { 2 - 4 } & 0.35 & 27 & II-II \\
\hline \multirow{3}{*}{ On the bottom } & 0.7 & 21 & II-III \\
\hline \multirow{3}{*}{ Double side } & Overlap & 114 & III-III \\
\cline { 2 - 4 } & 0.35 & 54 & III-III \\
\hline Untreated plate & 0.7 & 42 & $\mathrm{X}$ \\
\hline
\end{tabular}

Two different stress-strain curves and physical material properties (for base material and laser-treated tracks) were used for the FEA models (Table 3). The bending stand model was created as a three-point bending device according to ISO 7438:2016 [8]. The $60 \mathrm{~mm}$ distance between supports and $10 \mathrm{~mm}$ width of punch 10 $\mathrm{mm}$ was used. The two structural supports were modelled as movable roller supports (Figure 2 a). Boundary conditions: main support - fixed, 0 degree of freedom; punch - avaivlable displacement, 1 degree of freedom; metal plate - available displacement, 2 degree of freedom. The $2 \mathrm{~mm}$ maximum applied deflection was used.
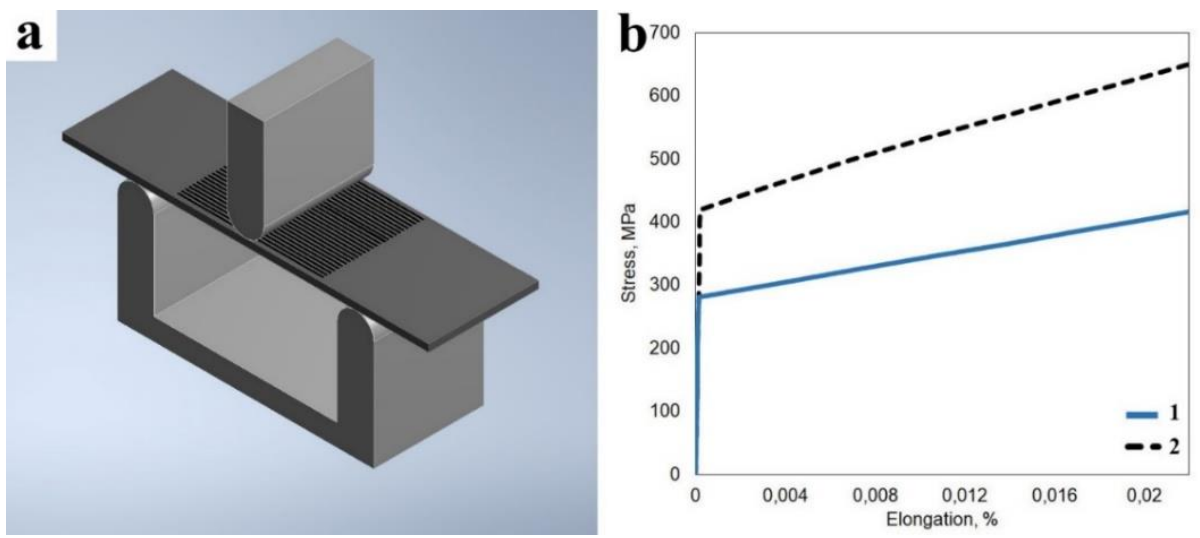

Figure 2 3D model of bending device a - general view; $b$ - stress-strain curves: 1 - base material, 2 - lasertreated area

Table 3 Mechanical properties of base metal and laser treated layer used to FEA simulation $[10,11,12]$

\begin{tabular}{|c|c|c|c|c|}
\hline Material & $\begin{array}{c}\text { Modulus of Elasticity } \\
\mathbf{E}(\mathbf{G P a})\end{array}$ & $\begin{array}{c}\text { Shear Modulus } \\
\mathbf{G}(\mathbf{G P a})\end{array}$ & $\begin{array}{c}\text { Yield strength } \\
\boldsymbol{\sigma}_{\mathbf{0} 2} \text { (MPa) }\end{array}$ & $\begin{array}{c}\text { Ultimate Strength } \\
\boldsymbol{\sigma}_{\mathbf{B}}(\mathbf{M P a})\end{array}$ \\
\hline Base metal & 200 & 78.1 & 275 & 440 \\
\hline Layer treated by layer & 210 & 82 & 412 & 665 \\
\hline
\end{tabular}

A mixture of 3D Solid brick and tetrahedral elements was used to mesh the model of the thin metal sheet. The untreated part of the model metal plate consisted mostly of large-scale elements. The maximum mesh size of untreated area was about $0.7 \mathrm{~mm}$. The mesh density of the treated area was increased. The maximum mesh size of treated area was less than $0.12 \mathrm{~mm}$. A Bilinear Isotropic Hardening model was used for the numerical 
investigation of the physically nonlinear problem $[9,13]$. The stress-strain curve of the basic metal is established experimentally. The stress-stain curve of the treated layer was predicted taking into account the data of hardness measurement and it relation with yield and tensile strain of metal. The dependences of the nonlinear part of the strain-stress curves are simplified to linear relevant for the Bilinear Isotropic Hardening model.

(Figure 2 b) [15].

\section{RESULTS}

The results of the FEA simulation are presented in Figures 3-6 and Table 4.
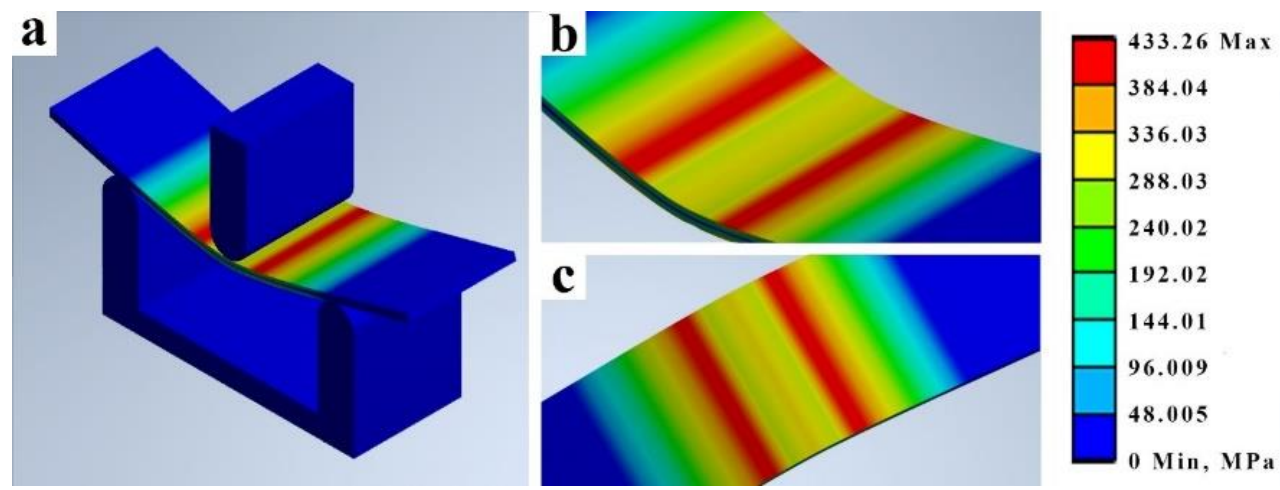

Figure 3 Distribution of internal stresses. Model of test sample $X$ (strain $1.0 \mathrm{~mm}$ ): a - general view, $b-$ top view of the plate, $c$ - bottom view
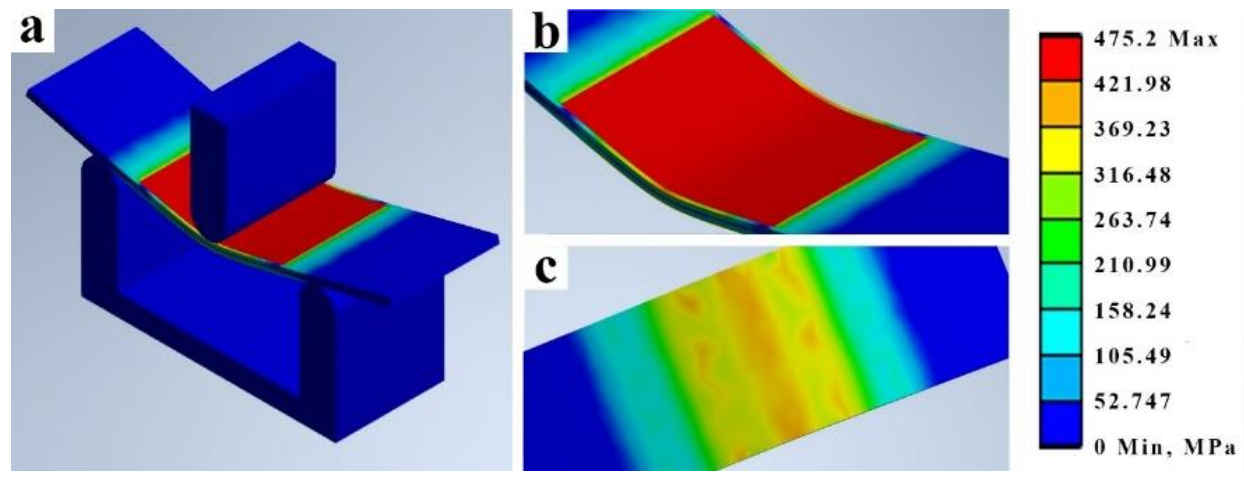

Figure 4 Distribution of internal stresses. Model of test sample I-I (strain $1.0 \mathrm{~mm}$ ): a - general view, b-top view of the plate, $\mathrm{c}$ - bottom view
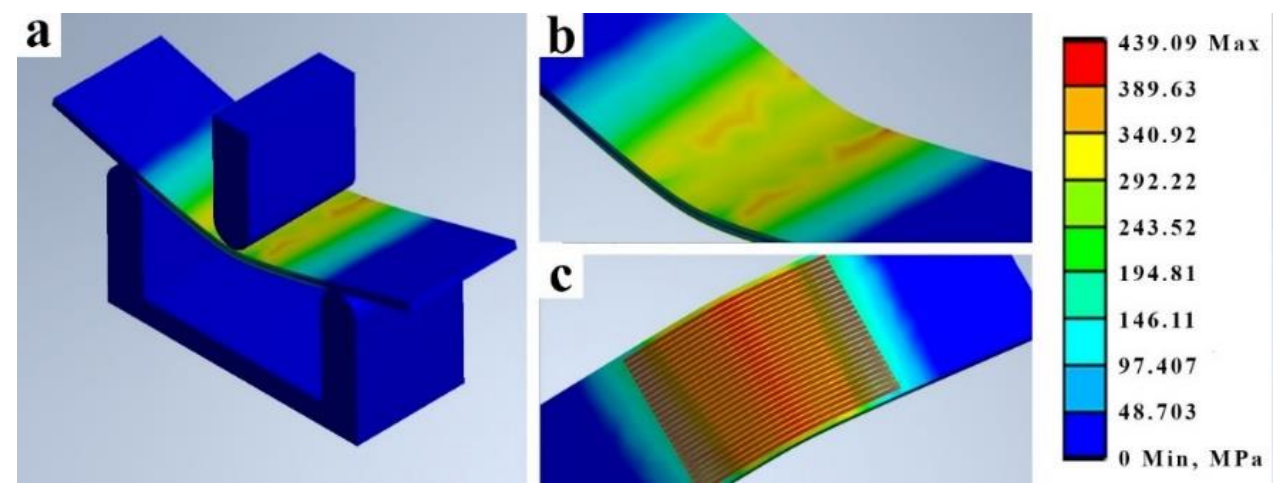

Figure 5 Distribution of internal stresses. Model of test sample II-II (strain $1.0 \mathrm{~mm}$ ): a - general view, b - top view of the plate, $\mathrm{c}$ - bottom view 

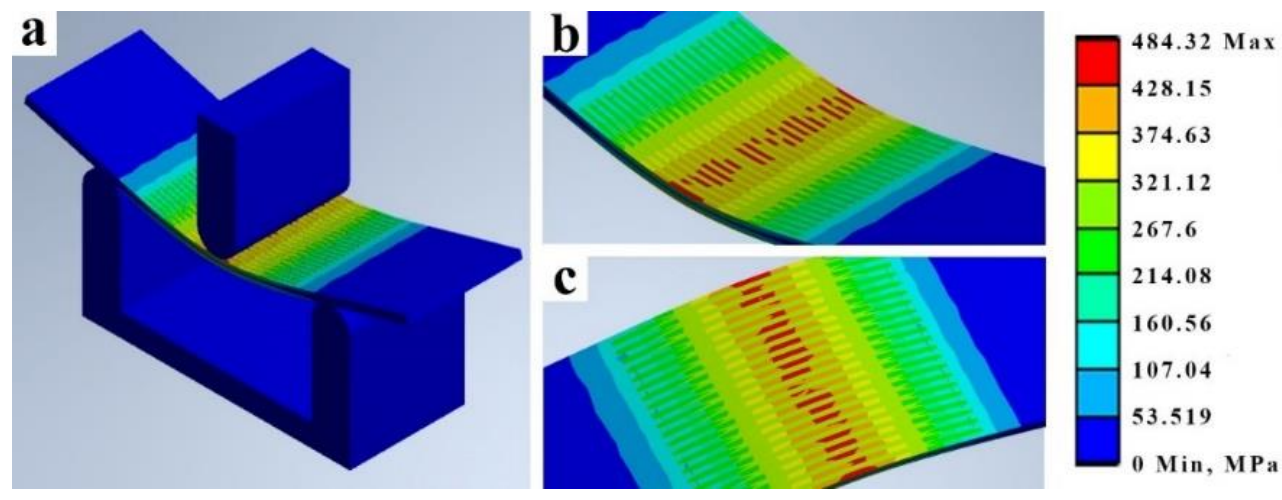

Figure 6 Distribution of internal stresses. Model of test sample III-III (strain $1.0 \mathrm{~mm}$ ): a - general view, b top view of the plate, $\mathrm{c}$ - bottom view

Table 4 Results of FEA simulation of the elastoplastic deformation

\begin{tabular}{|c|c|c|c|c|}
\hline Bending strain $(\mathrm{mm})$ & 0.5 & 1.0 & 1.5 & 2.0 \\
\hline \multicolumn{5}{|c|}{ Untreated sample (X) } \\
\hline Von Mises equivalent stress (MPa) & 306.1 & 418.05 & 421.89 & 433.26 \\
\hline Bending force $(\mathrm{N})$ & 391.99 & 683.45 & 786.69 & 843.7 \\
\hline \multicolumn{5}{|c|}{ Treated sample I-I } \\
\hline Von Mises equivalent stress (MPa) & 328.89 & 442.6 & 446.13 & 480.17 \\
\hline Bending force $(\mathrm{N})$ & 453.39 & 725.65 & 846.26 & 902.64 \\
\hline \multicolumn{5}{|c|}{ Treated sample I-II } \\
\hline Von Mises equivalent stress (MPa) & 321.67 & 431.59 & 434.73 & 459.61 \\
\hline Bending force $(\mathrm{N})$ & 435.61 & 713 & 808.65 & 875.86 \\
\hline \multicolumn{5}{|c|}{ Treated sample I-III } \\
\hline Von Mises equivalent stress (MPa) & 315.82 & 421.19 & 431.37 & 439.09 \\
\hline Bending force $(\mathrm{N})$ & 425.57 & 693.67 & 804.23 & 847.82 \\
\hline \multicolumn{5}{|c|}{ Treated sample II-I } \\
\hline Von Mises equivalent stress (MPa) & 332.45 & 442.64 & 453.32 & 484.32 \\
\hline Bending force $(\mathrm{N})$ & 455.22 & 727.06 & 861.36 & 917.23 \\
\hline \multicolumn{5}{|c|}{ Treated sample II-II } \\
\hline Von Mises equivalent stress (MPa) & 322.13 & 433.72 & 438.35 & 459.82 \\
\hline Bending force $(\mathrm{N})$ & 440.8 & 713.45 & 827.4 & 876.67 \\
\hline \multicolumn{5}{|c|}{ Treated sample II-III } \\
\hline Von Mises equivalent stress (MPa) & 318.38 & 430.69 & 432.04 & 451.23 \\
\hline Bending force $(\mathrm{N})$ & 428.9 & 698.02 & 806.23 & 873.7 \\
\hline \multicolumn{5}{|c|}{ Treated sample III-I } \\
\hline Von Mises equivalent stress (MPa) & 340.92 & 446.23 & 471.5 & 489.72 \\
\hline Bending force $(\mathrm{N})$ & 469.7 & 776.66 & 897.98 & 958.24 \\
\hline \multicolumn{5}{|c|}{ Treated sample III-II } \\
\hline Von Mises equivalent stress (MPa) & 324.08 & 440.94 & 444.32 & 475.2 \\
\hline Bending force $(\mathrm{N})$ & 452.57 & 720.42 & 838.53 & 898.94 \\
\hline
\end{tabular}




\begin{tabular}{|c|c|c|c|c|}
\hline \multicolumn{5}{|c|}{ Treated sample III-III } \\
\hline Von Mises equivalent stress (MPa) & 323.43 & 436.78 & 440.31 & 470.92 \\
\hline Bending force (N) & 442.4 & 714.66 & 835.76 & 893.02 \\
\hline
\end{tabular}

The analysis of data from Table 4 shows that the greatest strengthening effect was achieved when the sheet steel was treated by laser from both sides with overlapping of laser tracks. The difference of achieved maximal mechanical stresses in the samples treated from both sides in comparison with untreated sheet was up to 12 $\%$. The maximum value of applied bending force required for bending of both-side treated samples was up to $20 \%$ greater than for untreated samples. However, the differences of application efficiency of laser treatment with overlapping and discontinuous surface treatment (with different distances between laser tracks) are very small. Therefore, the technique of laser treatment with different distances between laser tracks is more reasonable and economical, because a smaller volume of metal was melted or heated, a smaller heat-affected zone was affected and lower thermal deformation of the product were achieved.

\section{CONCLUSIONS}

The results of FEA simulations of elastoplastic deformation of bended steel sheet shows that local laser processing can be used to strengthen thin sheet from hypoeutectoid steel C25E by up to $13 \%$, as an alternative to the application of complex geometric shape or additional strengthening elements. The FEA simulation can be used for the prediction of the required laser treatment area (geometry and localization of processed area, depth of laser penetration, orientation, and quantity of laser tracks) on the particular material.

\section{REFERENCES}

[1] JÄRVENPÄÄ, A., JASKARI, M., HIETALA, M., MÄNTYJÄRVI, K. Local Laser Heat Treatments of Steel Sheets. Physics Procedia. 2015, vol. 78, pp. 296-304.

[2] ELAGINA, O. Technological Methods To Improve The Wear Resistance Of Machine Part. Russia: Logos, 2009.

[3] KAPUSTYNSKYI, O., VIŠNIAKOV, N., ČERNAŠĖJUS, O., GOLOVKO, L., CHAYEUSKI, V. Optimization of the Parameters of Local Laser Treatment for the Creation of Reinforcing Ribs in Thin Metal Sheets. In MECHANIKA 2019: 24th International Conference. Moscow: Mysl, 2019 , pp. 71-75.

[4] Worldsteel.org. Fact Sheet. Advanced steel applications [online]. [viewed 2020-05-10] Available from: https://www.worldsteel.org/en/dam/jcr:4864507f-7f52-446b-98d6f0ac19da8c6d/fact Advanced $\% 2520$ steell\%2520applications 2018.pdf.

[5] ALLWOOD, J., CULLEN, J., CARRUTH, M. Sustainable Materials. Cambridge: UIT Cambridge, 2012.

[6] European Committee for Standardization. EN 10083-2:2006-10: Steels for quenching and tempering - Part 2: Technical delivery conditions for non alloy steels. Brussels: CEN, 2006.

[7] Azom.com. AISI 1025 Carbon Steel (UNS G102500) [online]. [viewed 2020-05-15] Available from: https://www.azom.com/article.aspx?ArticlelD=6582.

[8] International Organization for Standardization. ISO 7438: 2016: Metallic materials—Bend Test. Geneva: International Organization for Standardization, 2016.

[9] Fea-cae-engineering.com. Element Types [online]. [viewed 2020-05-23] Available from: http://fea-caeengineering.com/FEA-CAE-Engineering/element types.htm.

[10] ZHUKOV, A.A.,, LUZHNIKOV, A.P., DYINKINA, S.Ya. Engineering materials. Moscow: Mashinostroenie, 1967.

[11] DVORKIN, L.I. Building materials science. Russian-English Reference Book. Moscow-Vologda: Infra-Inzheneriya, 2017.

[12] TSIKLIS, D.S. Technique of physical and technical research at high and ultrahigh pressures. Moscow: Himiya, Russia. 1965; pp. 15-17.

[13] JONES, R. Deformation Theory of Plasticity. Blacksburg: Bull Ridge Pub., 2009.

[14] KAPUSTYNSKYI, O., VIŠNIAKOV, N. Laser Treatment for Strengthening of Thin Sheet Steel. Advances in Materials Science and Engineering, 2020, pp.1-13. 